\title{
Accuracy of Ultrasonographically Measured Placental Thickness in Third Trimester for Estimation of Gestational Age: A Cross Sectional Study Among Indian Population
}

\author{
Richa Sharma ${ }^{1, *}$, Natasha Gupta ${ }^{2}$ \\ ${ }^{1}$ Department of Obstetrics \& Gynaecology, University College of Medical Sciences \& Guru TegBahadur Hospital, Delhi, India \\ ${ }^{2}$ Department of Radiology, University College of Medical Sciences \& Guru TegBahadur Hospital, Delhi, India
}

\section{Email address:}

gautamdrricha1@gmail.com (R. Sharma), natashagupta@gmail.com (N. Gupta)

*Corresponding author

\section{To cite this article:}

Richa Sharma, Natasha Gupta. Accuracy of Ultrasonographically Measured Placental Thickness in Third Trimester for Estimation of Gestational Age: A Cross Sectional Study Among Indian Population. International Journal of Medical Imaging.

Vol. 5, No. 1, 2017, pp. 5-8. doi: 10.11648/j.ijmi.20170501.12

Received: January 13, 2017; Accepted: February 27, 2017; Published: March 15, 2017

\begin{abstract}
Exact determination of gestational age is of great clinical importance to the Obstetricians, dilemma remains in those women having unreliable LMP or having no early dating scans. A cross sectional study was done on 202 antenatal women in the third trimester (29 - 40 weeks), to evaluate the accuracy of ultrasonographically measured placental thickness in the third trimester for the estimation of gestational age in normal singleton pregnancies. It was found that Placental thickness gradually increased and corresponded with period of gestation from 29 to 38 weeks and then either it was constant or 1-2 mm lower than the period of gestation. Placental thickness is an effective ultrasonographic parameter for estimation of gestational age.
\end{abstract}

Keywords: Placental Thickness, Gestational Age, Ultrasonographic Parameter

\section{Introduction}

Many antenatal women in India report for their first antenatal check up in third trimester and may have unreliable last menstrual period or no early scan. Decision for induction of labour for any obstetric indication becomes difficult in these women. Wrong estimation of gestational age can errorously lead to unnecessary induction of labour, dysfunctional labour, caesarean section, increased maternal and neonatal morbidity. Unnecessary preterm inductions can also cause neonatal mortality due to consequences of prematurity. Placental thickness appears to be a promising ultrasonographic parameter for estimation of gestational age $[1,2]$. The Placenta is the physiologic link between the baby and the mother and its development occurs at $5^{\text {th }}$ week of embryonic life from the chorionic villi at the implantation site [3].It is a fetal organ with important endocrine, metabolic and immunologic function, apart from nutrition, respiration, and excretion. At term the placenta is nearly $3 \mathrm{cms}$ thick and measures $15-25 \mathrm{cms}$. Placental thickness is closely related to fetal wellbeing.
Large placentas are associated with severe anaemia, intrauterine infection, hemolytic diseases of newborn and maternal diabetes. Small placentas may be seen in severe maternal diabetes, chrosomal anomalies, growth restricted fetuses etc. Placental thickness gradually increase with gestational age in a linear fashion and the maximum thickness of a normal placenta at any point of time is considered to be $4 \mathrm{cms}$ [4].

We had undertaken a study to evaluate the accuracy of $3^{\text {rd }}$ trimester ultrasonographically measured placental thickness for estimation of gestational age.

Aim

To study the accuracy of ultrasonographically measured placental thickness in the third trimester by comparing it with last menstrual period and crown rump length measured in first trimester in the same women, for the estimation of gestational age in normal singleton pregnancies.

\section{Material and Methods}

A cross sectional study was conducted on antenatal women 
of any age and parity in third trimester (29 - 40 weeks) attending OPD for regular check up and satisfying inclusion criteria. Prior ethical clearance was taken from Institutional ethical committee. Gestational age was calculated from confirmed Last menstrual period (LMP) and Crown rump length (CRL), those having discrepancy of more than 2 weeks were excluded.

Inclusion criteria

1. All women with confirmed last menstrual period, regular cycles and not used hormonal pills 3 months prior to conception

2. Women having first trimester ultrasound

3. Low risk antenatal women

4. Singleton pregnancy

5. Women consenting to participate in the study

Exclusion criteria:

1. High risk pregnancies are excluded- hypertensive disorders, diabetes, fetal growth restriction, hydrocephalus, congenital anomalies etc.

2. Multiple gestation/ malpresentation/ Previous caesarean section.

Gestational age was calculated from confirmed LMP and $1^{\text {st }}$ trimester CRL and then correlated with $3^{\text {rd }}$ trimester measured placental thickness for calculation of gestational age. All sonographic examination was performed by a single sonographer using a standard USG machine with colour Doppler and transducer of 3.5 to $5.0 \mathrm{mHz}$. The Placental thickness was measured at the level of the umbilical cord insertion in the longitudinal direction and the mean of 3 readings was taken, as done by other researchers (4) (Fig 1, 2, 3, 4).

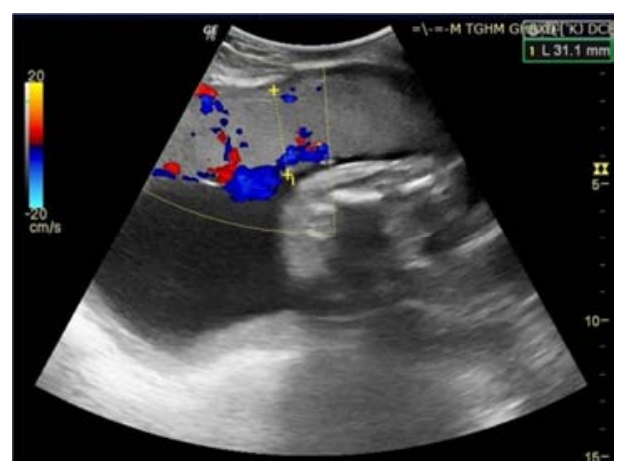

Figure 1. Placental thickness measurement with colour Doppler in anteriorly located placenta of Primigravida at 31 weeks gestation).

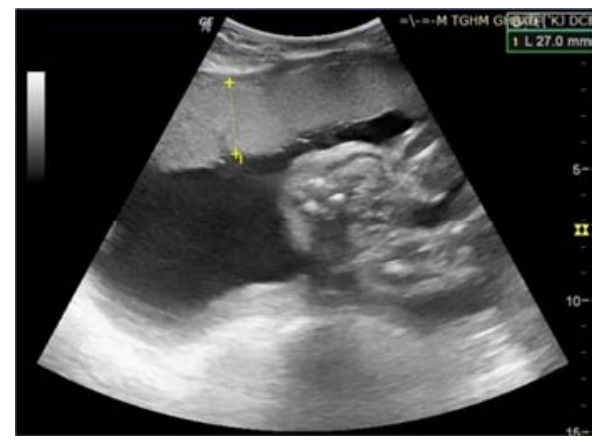

Figure 2. Placental thickness measurement without colour Doppler in anteriorly located placenta of Primigravida at $27+3$ weeks gestation.

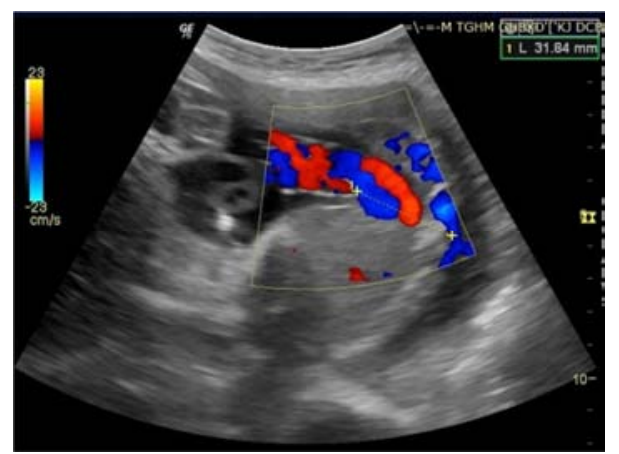

Figure 3. Placental thickness measurement with colour Doppler in posteriorly located placenta of G2P1L1 at 31+5 days gestation.

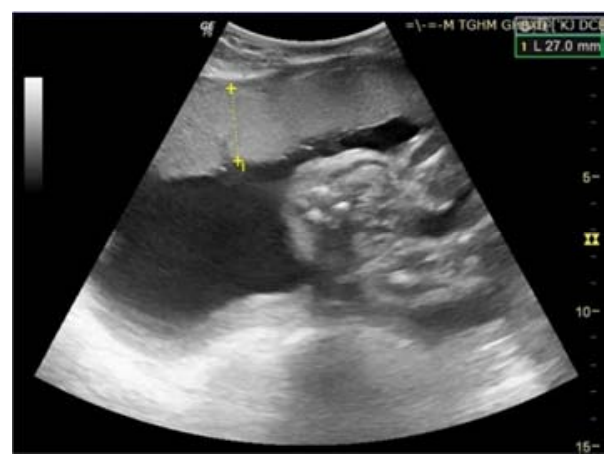

Figure 4. Placental thickness measurement without colour Doppler in posteriorly located placenta of a G3P2L1 at 26+6 weeks gestation.

Mean values and standard deviations were calculated for different gestational periods in $3^{\text {rd }}$ trimester.

\section{Results}

198 women were enrolled for the study, majority 118 (60\%) were $25-30$ years of age, followed by $19.1 \%$ women in 20-25 years group. Primigravida were 109 (55\%) and 89 (44.9\%) were multigravida (Table 1).

Table 1. Demographic profile.

\begin{tabular}{ll}
\hline Age & \\
\hline $20-25$ & $38(19.1 \%)$ \\
$25-30$ & $118(60 \%)$ \\
$30-35$ & $26(13.1 \%)$ \\
$>35$ & $16(8 \%)$ \\
Parity & \\
Primigravida & $109(55 \%)$ \\
Multigravida & $89(44.9 \%)$ \\
Gestational age (weeks) & \\
$29-30$ & $17(8.58 \%)$ \\
$30-31$ & $18(9 \%)$ \\
$31-32$ & $29(14.6 \%)$ \\
$32-33$ & $17(8.58 \%)$ \\
$33-34$ & $16(8 \%)$ \\
$34-35$ & $22(11.0 \%)$ \\
$35-36$ & $12(6.06 \%)$ \\
$36-37$ & $14(7.07 \%)$ \\
$37-38$ & $13(6.56 \%)$ \\
$38-39$ & $22(11.0 \%)$ \\
$39-40$ & $18(9 \%)$ \\
\hline
\end{tabular}

Women were grouped according to their gestational age, 
calculated by LMP. 69 (34.8\%) women had anteriorly located placenta, 48 (24.2\%) fundal and $81(40.9 \%)$ had posteriorly located placenta. It was found that Placental thickness gradually increased and corresponded with period of gestation from 29 to 38 weeks and then either it was constant or 1-2 mm lower than the period of gestation (Fig. 5).

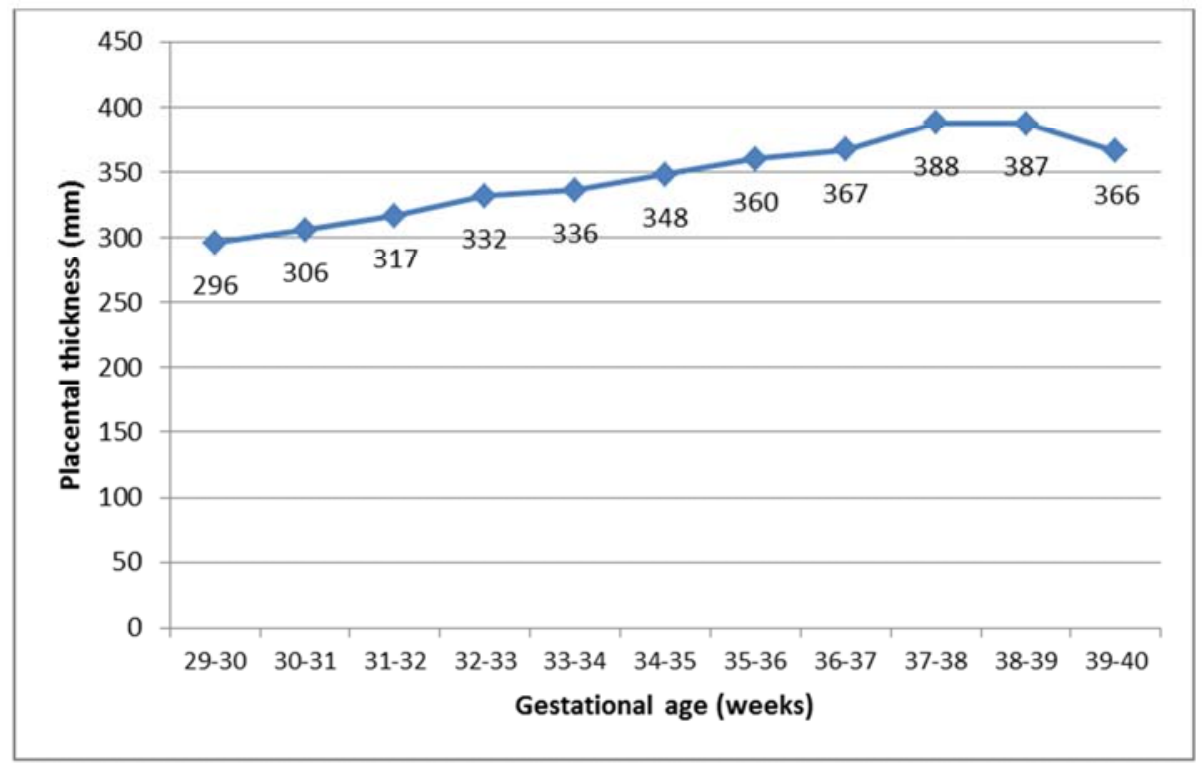

Figure 5. Distribution of gestational age and placental thickness Maximum thickness was 3.8 cms at 37-38 weeks.

\section{Discussion}

Exact determination of gestational age is of great clinical importance to the Obstetricians, dilemma remains in those women having unreliable LMP or having no early dating scans. Obstetrical ultrasound has been proved to be beneficial in two main aspects, being more accurate for dating and detection of fetal anatomic anomalies. Several normograms and formulas have been used for the assessment of gestational age and normal growth of fetal structures [5].

Various studies has been done to establish the effective ultrasonographic parameter that could reliably estimate the gestational age in any trimester. Placenta is technically defined as a apposition or fusion of fetal organs to maternal tissue for the physiologic exchange, it is $2-4 \mathrm{cms}$ thick and weigh nearly $600 \mathrm{gms}$ at term. The Placental thickness appears to be promising parameter for reliably estimating the gestational age.

Ohagwu CCet al conducted a study to determine the relationship between placental thickness and gestational age and found that there is a linear increase in mean placental thickness with gestational age [6]. Mital $\mathrm{P}$ et al reported that upto 21 weeks, the mean placental thickness was slighter higher than the gestational age $(1-4 \mathrm{~mm})$ and it exactly corresponded between 22-35 weeks, thereafter mean placental thickness was $1-2 \mathrm{~mm}$ lower than the gestational age [1]. Jain et al reported that the mean Value of placental thickness increases with advancing gestation and exactly corresponds from 27 to 33 weeks [2]. Karthikeyan $\mathrm{T}$ et al studied 211 antenatal low risk women at 11- 40 weeks and found that the maximum mean placental thickness in the $1 \mathrm{st}$, 2nd, 3rd and the combined trimesters were $16.5 \mathrm{~mm}, 23.78$ $\mathrm{mm}, 35.81 \mathrm{~mm}$ and $28.49 \mathrm{~mm}$ respectively. There was a strong positive correlation between placental thickness and gestational age, with the correlation coefficient values for the 1st, 2nd and 3rd trimesters being $r=0.609, r=0.812$ and $r=$ 0.814 [7]. Mathai Betty M. evaluated the role of placental thickness for estimation of gestational age in two groups, group A (fetal weight $<2.5 \mathrm{~kg}$ ) and group B (fetal weight $>2.5 \mathrm{~kg}$ ). A positive correlation was found between placental thickness and ultrasonographic age in both the groups ( $\mathrm{p}$ value 0.01 ), with pearson's correlation coefficient ' $r$ ' value of 0.325 in group A and 0.135 in group B regression analysis yielded linear equation of relationship with placental thickness and gestational age in both the group. However Placental thickness was lower in group A between 26-27 weeks and 30-31 weeks, with mean values of $2.48 \pm 0.063$ $\mathrm{cm}$ ( $\mathrm{p}$ value of 0.042 ) and $2.76 \pm 0.552$ (p value of 0.05 ) in group A compared to $3.04 \pm 0.25$ and $3.13 \pm 0.183 \mathrm{~cm}$ in group B [4].

Another study also found significant positive correlation between placental thickness and estimated fetal weight in $2^{\text {nd }}$ and $3^{\text {rd }}$ trimester [8]. Our study is consistent with previous studies and has been found that approximate gestational age in weeks corresponds to placental thickness in $\mathrm{mm}( \pm 10$ $\mathrm{mm}$ ). Damodaram M, found reduced but positive correlation between same association in growth restricted fetuses. The subnormal placental thickness for a gestational age may be the earliest indicator of growth restriction [9]. The cause of decreased placental size could be preeclampsia, severe maternal diabetes, chromosomal anomalies, chronic fetal infection and fetal growth restriction. Have suggested uterine artery Doppler along with placental thickness measurement for prediction of estimated fetal weight in growth restricted fetuses [10]. The placenta plays a very important role in the child birth process. A placenta of greater than $4 \mathrm{~cm}$ in 
thickness was regarded as abnormal [11]. Ohagwu CCet al also reported that maximum placental thickness was $45.09 \pm$ $6.37 \mathrm{~mm}$ at 39 weeks, Mahmoud S. Babiker et al also evaluated antenatal women between $12-40$ weeks and found that the maximum thickness to be $39.6 \pm 7.0 \mathrm{~mm}$ at $37-40$ weeks $[6,12]$. Our study found that maximum thickness was $3.8 \mathrm{cms}$ at 37-38 weeks, thereafter it declines.

\section{Conclusion}

Placental thickness is an effective ultrasonographic parameter to calculate gestational age at any period of gestation and it can be used with certainty among women with unreliable last menstrual period or not having early dating scans.

\section{References}

[1] Mital P, Hooja N, Mehndiratta K. Placental thickness: a sonographic parameter for estimating gestational age of the fetus. Indian J Radiol Imaging 2002; 12 (4): 553-4.

[2] Jain A, Kumar G, Agarwal U. Placental thickness: a sonographic indicator of gestational age. J ObstetGynaecol India 2001; 51 (3): 48-9.

[3] Cunningham FG, Leveno KJ, Bloom SL, Spong CY, Dashe JS, Hoffman BL, et al. Embryogenesis and fetal morphological development. In: Cunningham FG, Leveno KJ, Bloom SL, Spong CY, Dashe JS, Hoffman BL, editors. Williams Obstetrics, $24^{\text {th }}$ ed. New York: McGraw Hill; 2014. p. 127-155.

[4] Mathai BM, Singla SC, Nittala PP, Chakravarti RJ, Toppo JN.
Placental thickness: its correlation with ultrasonographic gestational age in normal and intrauterine growth-retarded pregnancies in the late second and third trimester. J ObstetGynaecol India 2013; 63 (4): 230-3.

[5] Rumack CM, Wilson SK, Charboneau JN. In fetal measurements-normal and abnormal fetal growth, diagnostic ultrasound-obstetric and fetal sonography. 3rd ed. St. Louis: ElsevierMosby; 2005. p. 1499-500.

[6] Ohagwu CC, Abu PO, Ezeokeke UO, Ugwu AC. Relationship between placental thickness and growth parameters in normal Nigerian foetuses. Afr J Biotechnol 2009; 8 (2): 133-8.

[7] Karthikeyan T, Subramaniam RK, Johnson W, Prabhu K. Placental thickness \& its correlation to gestational age \& foetal growth parameters- a cross sectional ultrasonographic study. J Clin Diagn Res 2012; 6 (10): 1732-5.

[8] Abu PO, Ohagwu CC, Eze JC, et al. Correlation between placental thickness and estimated fetal weight in Nigerian women. Ibnosina J Med Biomed Sci. 2009; 1 (3): 80-5.

[9] Damodaram M, Story L, Eixrach E. Placental MRI in intrauterine fetal growth restriction. Placenta. 2010; 31 (6): 91-498.

[10] Habib FA. Prediction of low birth weight infants from ultrasound measurement of placental diameter and placental thickness. Ann Saudi Med. 2002; 22 (5-6): 312-14.

[11] Anna J. Lee, MBBS, FRANZCOG et al. Placental Thickness in the Second Trimester; A Pilot Study to Determine the Normal Range, JUM., 31 (2), (2012), 213-218.

[12] Mahmoud S. Babiker, Rana A Eisa Placenta Thickness Measurements during Gestational Age Progress. Journal of Applied Medical Sciences, vol. 3, no. 1, 2014, 31-37 ISSN: 2241-2328 (print version), 2241-2336 (online) Scienpress Ltd, 2014. 